Article

\title{
Experimental and Theoretical Evidence for Surface-Induced Carbon and Nitrogen Fractionation during Diamond Crystallization at High Temperatures and High Pressures
}

\author{
Vadim N. Reutsky ${ }^{1, *}$, Piotr M. Kowalski ${ }^{2}$, Yury N. Palyanov ${ }^{1,3}$, EIMF $^{4}$ and \\ Michael Wiedenbeck ${ }^{5}$ \\ 1 Sobolev Institute of Geology and Mineralogy SB RAS, Novosibirsk 630090, Russia; palyanov@igm.nsc.ru \\ 2 Institute of Energy and Climate Research (IEK-6), Forschungszentrum Juelich, 52425 Juelich, Germany; \\ p.kowalski@fz-juelich.de \\ 3 Department of Geology and Geophysics, Novosibirsk State University, Novosibirsk 630090, Russia \\ 4 Edinburgh Ion Microprobe Facility, Grant Institute of Earth Sciences, School of GeoSciences, \\ University of Edinburgh, Edinburgh EH9 3JW, UK; jcraven@staffmail.ed.ac.uk \\ 5 Deutsches GeoForschungZentrum, 14473 Potsdam, Germany; michael.wiedenbeck@gfz-potsdam.de \\ * Correspondence: reutsky@igm.nsc.ru; Tel.: +7-383-3306531
}

Academic Editor: Helmut Cölfen

Received: 31 March 2017; Accepted: 22 June 2017; Published: 26 June 2017

\begin{abstract}
Isotopic and trace element variations within single diamond crystals are widely known from both natural stones and synthetic crystals. A number of processes can produce variations in carbon isotope composition and nitrogen abundance in the course of diamond crystallization. Here, we present evidence of carbon and nitrogen fractionation related to the growing surfaces of a diamond. We document that difference in the carbon isotope composition between cubic and octahedral growth sectors is solvent-dependent and varies from $0.7 \%$ in a carbonate system to $0.4 \%$ in a metal-carbon system. Ab initio calculations suggest up to $4 \%$ instantaneous ${ }^{13} \mathrm{C}$ depletion of cubic faces in comparison to octahedral faces when grown simultaneously. Cubic growth sectors always have lower nitrogen abundance in comparison to octahedral sectors within synthetic diamond crystals in both carbonate and metal-carbon systems. The stability of any particular growth faces of a diamond crystal depends upon the degree of carbon association in the solution. Octahedron is the dominant form in a high-associated solution while the cube is the dominant form in a low-associated solution. Fine-scale data from natural crystals potentially can provide information on the form of carbon, which was present in the growth media.
\end{abstract}

Keywords: mixed-habit diamond crystallization; carbon isotopes; nitrogen impurity; fractionation; experiment; high pressure; high temperature; crystal chemistry; surface structure; SIMS

\section{Introduction}

Compositional inhomogeneity of both natural and synthetic diamond crystals is a well-established phenomenon. Two models for explaining a heterogeneous distribution of carbon isotopes and key impurities within diamond crystals have been debated: changing of the carbon source and fractionation of a fluid over the course of diamond crystallization. Both of these models require marked changes in fluid composition as the driving factor for generating shifts in the carbon isotope ratio and/or the abundances of impurities, the most important of which being nitrogen. A comparison of synthetic and natural crystals reveals some key features that can be obvious for synthetic crystals but which are extremely rare in natural diamonds. First, a strong sectorial distribution pattern for nitrogen 
both in terms of concentration and isotopic composition has been observed in high temperature and high pressure (HTHP) synthetic diamonds [1-5]. It is also known that the growth of diamonds along the [100] direction during chemical vapour deposition (CVD) synthesis leads to lowering the impurities level in the crystal in comparison with material grown along [111] direction [6]. Less dramatic but consistent sectorial carbon isotope distribution between octahedra and cube growth sectors has also been documented in HTHP synthetic diamonds [2,5], whereas most attempts to observe such a compositional pattern in natural diamond crystals have been without success [7-9]. Sectorial variations in nitrogen abundance and carbon isotope ratios in natural mixed-habit diamond crystals were reported by Zedgenizov and Harte [10] for a diamond crystal from Udachnaya pipe and by Howell et al. [11,12] for three crystals from unknown locations. These data suggest that some compositional heterogeneity can occur in diamonds with no changing of fluid composition and at roughly equal kinetic conditions because simultaneously grown faces of the same crystal certainly feed from the same fluid. This particular case is the focus of the present research.

Until now, most investigated synthetic crystals come from metal-carbon systems that are highly efficient at diamond production $[1,13]$. Taking into account the general opinion of crystallization of natural diamonds from silicate/carbonate fluids [14], the difference in composition of the fluid/melt from which diamond grows in experiments and in the nature has brought into question the relevance of such experimental results for geochemistry. However, methods for producing synthetic diamonds from non-metallic systems have now become advanced enough to make such material available for investigation. Here, we present the results of a compositional investigation of diamond material obtained from carbonate system in high-pressure and high-temperature experiments. Together with more detailed data for crystals from metal-carbon systems, our results point to a measurable fractionation of carbon isotopes and nitrogen impurity on the surface of diamond itself, regardless of the bulk composition of the system. This conclusion is supported by ab initio calculations of carbon isotope fractionation on different crystallographic faces of diamond.

Further in the text, we will use the term "octahedral growth" to indicate diamond material grown by faces of octahedra and term "cubic growth" for sectors of growth of cube faces.

\section{Results}

\subsection{Cathodolumenesence}

As described in the "Samples and Methods" section, samples were cut parallel to the [110] direction to reveal internal structure, including growth zones and sectors, and, especially, to reveal the seed-to-rim relationship. The contrast in cathodolumenesence (CL) response between natural seeds and synthetic rims is clearly visible in Figure 1a,b. Sample 268-1 (octahedral to dodecahedral seed) grew by octahedral faces only (Figure 1a,c). The rim has a dark and relatively uniform CL image in comparison to the seed crystal. In the case of sample 268-2 (dodecahedral seed), octahedral sectors appear simultaneously with cubic sectors (Figure 1b,d). Growth sectors of faces $\{100\}$ show brighter $C L$ images in comparison with both the natural seed and growth sectors of faces $\{111\}$ (Figure 1a,b). All the seed-rim boundaries are sharp and linear, which means that no appreciable resorption of the seed crystals took place prior to overgrowth crystallization. As expected, seeds retained their shape and size through the experiments. 

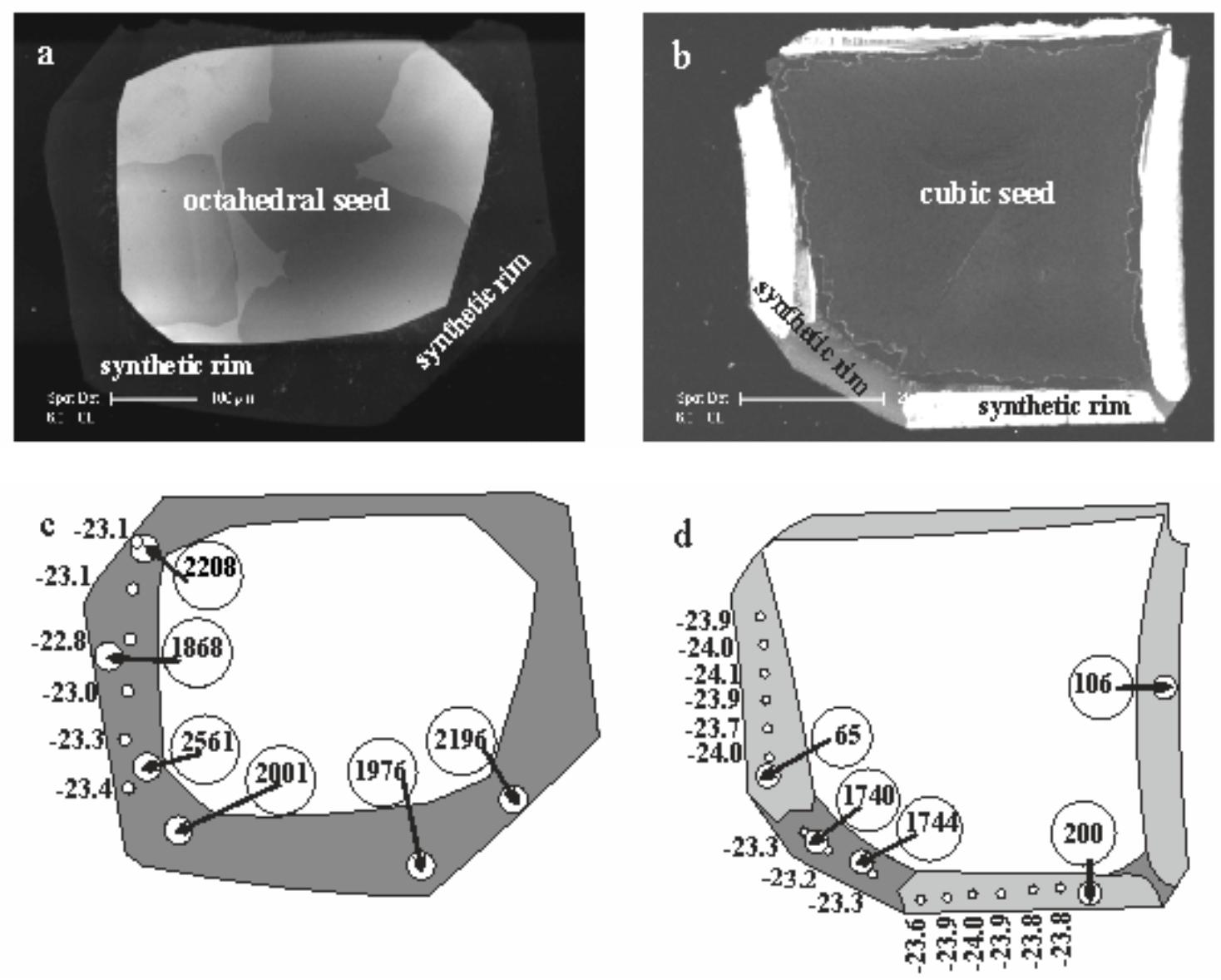

Figure 1. Cathodoluminescence images of investigated samples 268-1 (a) and 268-2 (b) and schematic pictures of synthetic rims (c,d). The cores represent seed crystals: 268-1—octahedral to dodecahedral seed crystal, 268-2 - cubic seed crystal. Rims grown from a single carbonate melt. On schemas, light-grey parts related to cubic growth and dark grey parts related to octahedral growth. Small circles indicate positions of carbon isotope analysis. Bigger circles correspond to positions of nitrogen analysis.

\subsection{Carbon Isotope Ratios by Secondary Ion Mass Spectrometry (SIMS)}

We have collected a comprehensive carbon isotope data from all the observed segments of the crystals, including seeds, sectors of octahedral and of the cube (Table S1). The seed crystals have average carbon isotope compositions $-5.4 \%$ for sample $268-1$ and $-2.3 \%$ for sample $268-2$, which are normal for natural diamonds. Despite quite complex internal structures within the seed crystals that are revealed with CL, it was no reason for detailed investigation of these parts of the samples. Limited data were collected in order to evaluate the contrast of natural and synthetic material. Carbon isotope composition of synthetic diamond rims is distinctly different from that of the seeds. The rim in sample 268-1 grew by octahedral growth only and this material shows $\delta^{13} \mathrm{C}$ values from -22.5 to -23.4 (mean $-23.03 \%$, $\mathrm{sd}=0.29, n=15$ ). The synthetic rim in sample $268-2$ consists of sectors of both octahedral and cubic growth. The octahedral growth rim material shows $\delta^{13} \mathrm{C}$ values from -23.19 to -23.33 (mean $-23.27 \%$, sd $=0.07, n=3$ ), whereas the $\delta^{13} \mathrm{C}$ values obtained for cubic growth of sample $268-2$ vary from -23.6 to -24.1 (mean $-23.88 \%$, $\mathrm{sd}=0.14, n=14$ ). The carbon isotope composition of octahedral growth diamond in both samples is equal. The cubic growth diamond shows statistically more negative $\delta^{13} \mathrm{C}$ value in comparison with octahedral growth (Table 1 ) and the difference of $0.8 \%$ exceeds the analytical uncertainties $(0.24 \% 0)$. 
Table 1. Summarized SIMS data of $\delta^{13} \mathrm{C}$ and nitrogen abundances measured within synthetic rims of diamonds grown from carbonate fluid. Statistics account for all the data available for particular crystallography in both 268-1 and 268-1 samples.

\begin{tabular}{ccccc}
\hline \multirow{2}{*}{ Sample } & \multicolumn{2}{c}{ Octahedral Growth } & \multicolumn{2}{c}{ Cubic Growth } \\
\cline { 2 - 5 } & $\boldsymbol{\delta}^{\mathbf{1 3}} \mathbf{C}(\%)$ & $\mathbf{N}$ (at. $\mathbf{p p m})$ & $\boldsymbol{\delta}^{\mathbf{1 3}} \mathbf{C}(\%)$ & $\mathbf{N}$ (at. ppm) \\
\hline mean & -23.07 & 1536 & -23.88 & 70 \\
st.dev. & 0.28 & 375 & 0.14 & 41 \\
$n$ & 18 & 27 & 14 & 18 \\
\hline
\end{tabular}

\subsection{Ab Initio Calculations of Carbon Isotope Fractionation}

Considering the role of growing surfaces for carbon isotope fractionation during diamond crystallization, we perform an ab initio calculation of carbon isotope equilibrium. Uncertainty concerning the carbon position in a solution makes it impossible to calculate directly the fractionation between a solution and a crystal. Instead, we calculated carbon isotope fractionation between atomic positions within the crystal lattice and selected faces of a diamond. This approach makes possible a comparison of particular faces of a diamond crystal in terms of carbon isotope affinity regardless of solution composition. Results from these computations are shown in Figure 2. Remarkably, the surface of a cube is the most favorable for ${ }^{12} \mathrm{C}$ capture. In the first layer, the instantaneous difference in $\delta^{13} \mathrm{C}$ between cube and octahedra is expected to be $3.75 \%$ at $1400 \mathrm{~K}$, and this decreases to $1.85 \%$ at $2000 \mathrm{~K}$. This difference disappears completely once one models seven or more layers below the crystal surface. Octahedron and rhombododecahedron surfaces display complicated relationships with a changeover in the affinity of ${ }^{12} \mathrm{C}$ isotope arising at the fifth layer inside the crystal lattice (Figure 2). However, a clear qualitative difference of certain isotope affinity between faces of cubes and of octahedra can be traced at least down to the fifth layer.

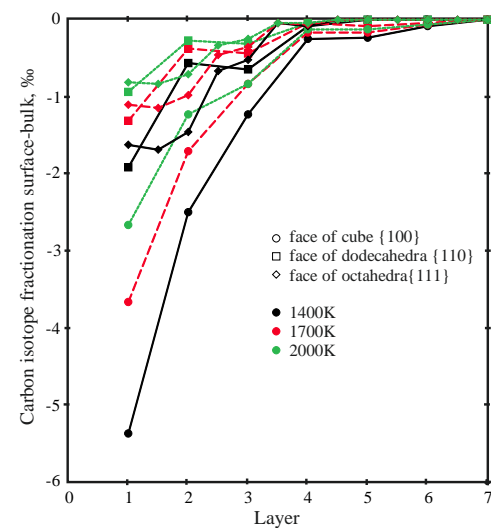

Figure 2. Results of ab initio calculation of isotope equilibrium of carbon positions on particular crystallographic face of diamond crystal in comparison with deeply sited positions in diamond lattice (bulk) at different temperatures.

\subsection{Nitrogen Abundances}

All the determined nitrogen results are given in Table S1. Nitrogen abundance in the seed crystals varies from 824 to $1516 \mathrm{ppm}$ in sample 268-1 and from 1163 to $1370 \mathrm{ppm}$ in sample 268-2. The nitrogen content in the synthetic layer of sample 268-1 ranges from 1116 to $2561 \mathrm{ppm}$ (mean $1575 \mathrm{ppm}$, sd = 395, $n=21$ ). Growth sectors of octahedra in sample 268-2 are rather small, but the nitrogen content in these sectors range from 1112 to $1744 \mathrm{ppm}$ (mean $1401 \mathrm{ppm}, \mathrm{sd}=281, n=6$ ), which is very similar to those obtained from the synthetic layer of sample 268-1. SIMS analysis points within cube growth sector in sample 268-2 all yielded low nitrogen concentrations ranging from 16 to $200 \mathrm{ppm}$ (mean $70 \mathrm{ppm}$, 
$\mathrm{sd}=41, n=18)$. The difference in nitrogen abundance can clearly be seen between octahedral and cubic growth sectors (Table 1). Similar to carbon, nitrogen characteristics of octahedral grown diamond in both samples are equal, but cubic grown diamond is significantly depleted in nitrogen overall.

\section{Discussion}

Nitrogen distribution shows a strong sector dependence in synthetic diamond crystals [1-5,15]. Sectors of octahedra were always enriched in nitrogen in comparison with sectors of other forms, including cube, trapezohedra and rhombododecahedra. As mentioned, previously published works considered diamond crystals grown in metal-carbon systems only. In the present study, we report first data collected from diamonds grown in a carbonate system.

A marked difference of nitrogen content reaching over a factor of 10 is clearly seen between cubic and octahedral growth diamond from carbonate system. The value for this difference cannot be precisely established due to the limited dataset for cubic growth, but the overall pattern is the same for diamond crystals from metal-carbon and carbonate systems (Table 2). This difference is also confirmed by the data from different SIMS laboratories, which fit each other well in both carbon isotopes and nitrogen abundances.

Table 2. Summary of available data on compositional difference between sectors of growth of octahedra and other crystallographic faces within synthetic diamond single crystals. Methods of data collecting are emphasized: IR—infra-red spectroscopy; MS—convenient bulk combustion with mass-spectrometry; SIMS—-secondary ion mass-spectrometry.

\begin{tabular}{cccc}
\hline System & $\delta^{\mathbf{1 3}} \mathbf{C}_{\mathbf{1 1 1}}-\delta^{\mathbf{1 3}} \mathbf{C}_{\mathbf{1 0 0}}$ & $\mathbf{N}_{\mathbf{1 1 1}} / \mathbf{N}_{\mathbf{1 0 0}}$ & Source \\
\hline Carbonate & 0.8 & $\sim 20$ & $\begin{array}{c}\text { Present work } \\
\text { (SIMS) }\end{array}$ \\
\hline \multirow{2}{*}{ Metal-carbon } & 0.4 & $2.58-4.0$ & [5] (SIMS) \\
& about 0 & 2.87 & [2] (MS) \\
[3] (IR) \\
\hline Natural reduced conditions & - & 2.0 & [12] (SIMS) \\
\hline
\end{tabular}

Like nitrogen, the carbon isotope composition also shows a measurable difference between cube and octahedra growth sectors. The use of a single carbon source under identical growth conditions for both investigated samples makes it reasonable to combine the data from octahedral growth in sample 268-2 and from octahedral growth in sample 268-1 to construct a single dataset. This approach makes for a more statistically robust comparison between octahedral and cubic growth. Our dataset shows that cubic growth diamonds are depleted in ${ }^{13} \mathrm{C}$ isotope in comparison to octahedral growth diamonds (Table 2, Figure 1). This difference is rather small but exceeds the analytical uncertainty of $\delta^{13} \mathrm{C}$ measurements, so it should be consider significant. A similar relationship also can be recognized for crystals grown in metal-carbon system [5]. In order to illustrate this, a detailed dataset for synthetic diamond crystals synthesized in a Fe-Ni-C system and where both octahedra and cube sectors grew simultaneously is shown in Table 3 . The cube sectors show systematic depletion by about $0.4 \%$ in heavy carbon isotope in comparison with an adjacent octahedral sector. The size of ${ }^{13} \mathrm{C}$ depletion of cubic sector for the carbonate system is about $0.7 \%$. The difference between the metal and carbonate systems is negligible and could be solvent dependent or growth rate dependent. What is important is that the direction and magnitude of the effect are the same in both metal-dominated and carbonate-dominated environments (Table 2).

The obvious similarities between the isotopic patterns of synthetic diamonds from both experimental systems provide evidence of no significant importance of solvent composition for distribution of nitrogen and carbon isotopes between octahedral and cubic growth diamond. By concluding that these effects are structurally defined, a generalized model describing the atomic structures of these particular faces on diamond crystals can be developed. 
Table 3. SIMS data of $\delta^{13} \mathrm{C}$ values measured in adjusted sectors of faces of octahedra and cube in synthetic diamond crystals from Fe-Ni-C system. See [5] for details.

\begin{tabular}{|c|c|c|c|c|c|}
\hline \multirow{2}{*}{ Sample } & \multicolumn{2}{|c|}{ Octahedra } & \multicolumn{2}{|c|}{ Cube } & \multirow{2}{*}{$\Delta, \%$} \\
\hline & Distance $^{*}, \mu \mathrm{m}$ & $\delta^{13} \mathrm{C}, \%$ & Distance ${ }^{*}, \mu \mathrm{m}$ & $\delta^{13} \mathrm{C}, \%$ & \\
\hline \multirow{5}{*}{$150 / 3 / 5$} & 1849 & -27.1 & 1825 & -27.4 & 0.4 \\
\hline & 2371 & -27.3 & 2380 & -27.4 & 0.1 \\
\hline & 2907 & -26.9 & 2934 & -27.3 & 0.4 \\
\hline & 3422 & -26.9 & 3405 & -27.2 & 0.4 \\
\hline & 3839 & -26.7 & 3828 & -27.4 & 0.7 \\
\hline \multirow{7}{*}{$140 / 4 / 6$} & 285 & -25.6 & 286 & -26.0 & 0.4 \\
\hline & 524 & -25.9 & 528 & -26.4 & 0.5 \\
\hline & 607 & -26.1 & 595 & -26.4 & 0.3 \\
\hline & 695 & -25.9 & 705 & -26.6 & 0.7 \\
\hline & 2120 & -26.5 & 2203 & -26.8 & 0.3 \\
\hline & 2492 & -26.4 & 2446 & -26.7 & 0.3 \\
\hline & 2865 & -26.2 & 2828 & -26.7 & 0.5 \\
\hline
\end{tabular}

* The distance is given as a projection of actual position of a SIMS spot to a line starting from the seed position and going perpendicular to octahedral growth zones. The diameter of SIMS spots is $20 \mu \mathrm{m}$.

3.1. Crystal Structure Characteristics and General Regularities of Carbon Isotopes and Impurities Incorporation into a Crystal

A crystal surface can grow either via the incorporation of single atoms or by attaching coordinated groups of atoms. In the first case, the structure and perfectness of the growing surface determine the fractionation of elements and isotopes. Overall, the fractionation is more pronounced upon lowering a linear growth rate of the surface [16]. In the second case, where carbon atoms have formed a group in a melt/fluid, only minor fractionation would be expected either between a solution and the groups of atoms or between the groups of atoms and the crystal. This process would provide a means for incorporating impurities into the growing crystal while avoiding any significant carbon isotope fractionation. Faces $\{111\},\{110\}$ and $\{100\}$ differ significantly in their arrangement of atoms and any fractionation of atoms or groups of atoms on attaching to these surfaces should not be equal. Therefore, we consider each of these surfaces separately.

The face of the cube $\{100\}$ has a single-layer atomic plane (Figure 3), where the surface consists of regularly distributed equal units. Atoms on a cubic face have no direct bonds with neighbours within the same plane but joined with two atoms of the previous plane and two atoms of the next plane. Thus, every unit cell on the growing face of the cube has two open bonds. Every subsequently produced atomic plane of $\{100\}$ will be identical to the previous one.
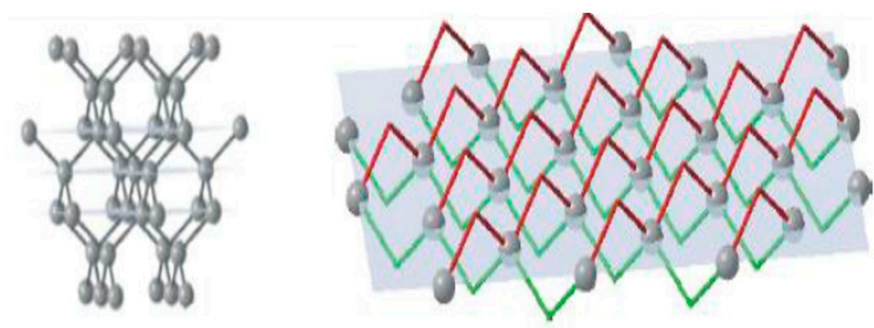

Figure 3. Atomic plane of cubic face.

The face of rhombododecahedra $\{110\}$ has a single-layer atomic plane that consists of zigzag-like chains of atoms (Figure 4). These chains are not bonded to each other, but every atom in the plane has one link to a previous atomic plane and one link to the next atomic plane. Thus, a growing rhombododecahedra face will consist of single-bond units where every newly formed atomic plane will be the same as the previous one. 

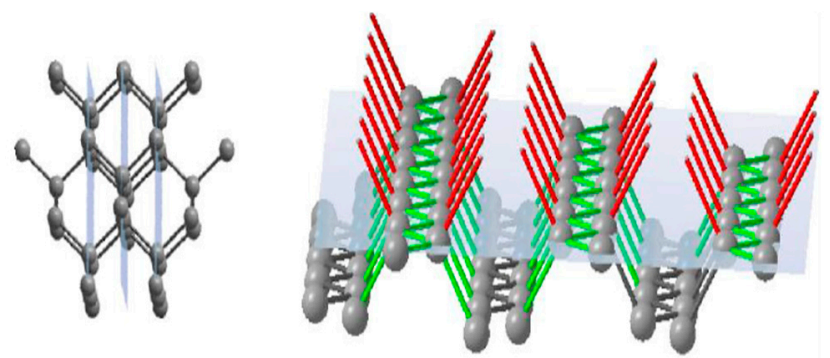

Figure 4. Atomic plane of rhombododecahedral face.

The face of octahedra $\{111\}$ has a double-layer atomic plane (Figure 5). Every single atom in this plane makes three joins with neighbour atoms of the same plane and one bond connected to the next atomic layer. It means that the growing surface of octahedra consists of a layer of triple-bond units followed by a layer of single-bond units.
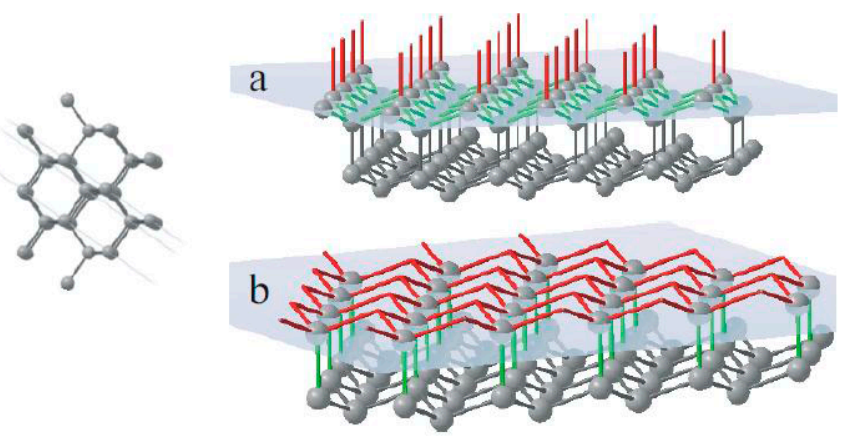

Figure 5. Atomic plane of octahedral face. (a)-layer of single-bond units; (b)-layer of triple-bond units.

In general, any crystallization from a solution will result from a supersaturation of a solvent by a component with respect to a certain crystal structure. Coordinated groups of atoms of a component can become stable in a solution under certain conditions. Such coordinated groups will have characteristics favouring their incorporation in a particular crystal structure: Composition of the solvent and solvent impurities will also influence the stability of particular coordinated groups of atoms. For example, an increasing abundance of nitrogen impurity in a diamond-producing metal-carbon melt will favour to crystallization of graphite instead of diamond [17].

A detailed investigation of crystallization of semiconductors with diamond-like structures reveals the importance of atomic clusters in solution [18]. The stability of specific coordinated groups of atoms is required to produce a perfect crystal. A few types of coordinated groups have been recognized in the case of diamond: one-dimension chains; two-dimension nets and three-dimension skeletons. These groups are rather stable in the solution, but can modify or rearrange until they are ultimately incorporated into the crystal lattice. Obviously, atoms from the solvent and other impurities could also take part in these groups. However, the presence of impurity atoms within such clusters leads to changes in both morphology and electron structure of the group, making it more difficult for such impurity-bearing groups to be incorporated onto crystal surface. Therefore, the availability of a perfect and regular structure on a growth surface will suppress the incorporation of groups of atoms holding impurities.

According to [18], when a matrix solution contains no associated carbon atoms, octahedral faces of the diamond will grow the fastest. This, in turn, leads to the slower growing cubic faces to dominate in such a low-associated solution. If pre-existing atomic clusters of carbon are common in a solution, then the octahedra form becomes dominant due to its slow growth rate in comparison with other 
directions. On the other hand, the highly ordered cube faces provide favorable conditions for the fractionation of atoms and groups of atoms [19]. In contrast, alternation of triple-bond and single-bond units on the growing surface of octahedra could make fractionation of atoms and groups of atoms less likely. In support, it has been shown that octahedra faces have less perfect structures as compared to cube faces in CVD diamonds [6]. Considering data for HPHT diamonds, growth sectors of cube, trapezohedra and rhombododecahedra are always depleted in impurities, including nitrogen, metals and other elements in comparison with growth sectors of octahedra [1-5].

\subsection{Ab Initio Calculations of Carbon Isotope Fractionation}

The results from our ab initio calculations provide strong support for ${ }^{12} \mathrm{C}$ isotope affinity to cubic growth diamond relative to octahedral crystal faces. The difference of $3.75 \%$ is expected within the first crystal layer at $1400 \mathrm{~K}$ (Figure 2). Instantaneous depletion of cubic face in heavy carbon isotope at about $1100{ }^{\circ} \mathrm{C}$ must be close to $4 \%$ in comparison to simultaneously growing octahedral faces. Again, it should be emphasized that the direction of fractionation is more important than the actual degree of isotope fractionation. It is well known from calculations [20-22] and from experiments [23] that diamond is enriched in heavy carbon isotope in a metal-carbon system but depleted in carbonate system in comparison with parent solution/fluid. However, the surface-induced relative fractionation is the same for both systems.

Theoretically, carbon isotope self-diffusion in the crystal lattice could erase this pattern since no energy difference between atom positions exists below the 6th atomic layer (Figure 2). However, self-diffusion of carbon isotopes in diamond is extremely slow [24], and, once generated, this pattern should remain for a long time even at mantle conditions. Such patterns have been reported in some natural diamonds [10,11]. Galimov [25] shows $\sim 3 \%$ depletion in ${ }^{13} \mathrm{C}$ of cuboid diamonds in comparison with octahedral crystals from Yakutian kimberlites, which might, at least in part, have resulted from the surface-induced crystallochemical fractionation discussed here. However, the major challenge in documenting considered feature within the natural samples is the relatively high carbon isotope heterogeneity typically found in natural diamond crystals. Furthermore, the very limited dataset reported at the nanogram sampling size with high spatial resolution make it difficult to make firm conclusions about such behavior in natural environments.

\subsection{Fractionation of Nitrogen}

As shown above, within a single crystal of synthetic diamond sectors of cube are significantly depleted in nitrogen in comparison with growth sectors of octahedra. Detailed SIMS traverses across growth sectors in synthetic diamonds from a metal-carbon system reveal the same distribution of nitrogen between $\{111\}$ and $\{100\}$ sectors [5]. Furthermore, sectors of octahedra show nitrogen abundances, which are close to that of the starting graphite [5,17]. Significant nitrogen depletion in cube sectors in comparison to nitrogen content in initial graphite documents the incompatible behavior of nitrogen in the 100 sector of diamond. These observations fit well with the incorporation of coordinated groups of carbon atoms containing nitrogen onto octahedral face with no efficient fractionation of nitrogen impurity, whereas the opposite is true for cube sectors. As mentioned above, the cube faces are dominant in a low-associated solution. Atom by atom incorporation of both carbon and nitrogen into well-ordered regular surfaces of cube provides the strongest discrimination against nitrogen incorporation. This pattern holds true for all synthetic samples investigated until now, including our current data for diamonds from the carbonate system. There are still no direct data reported on the actual nitrogen isotope fractionation between particular faces of diamond and the crystallization medium. The most important result from the above data is that surface-induced nitrogen fractionation is very much the same in metal-carbon and carbonate systems and the compositional difference between sectors of growth of different crystal faces has the same direction in both substrates.

There is a growing body of data documenting coupled variation of nitrogen concentration and carbon isotope fractionation during diamond growth [26-30]. It has been suggested that nitrogen 
behavior is influenced by both diamond growth rate [31] and $f \mathrm{O}_{2}$ [22]. According to "a limit sector" model [26], nitrogen must be generally incompatible in diamond at kinetic fractionation, since nitrogen content in diamonds suggested going lower with lowering diamond growth rate. Stachel et al. [27] argued that, in case of equilibrium fractionation, nitrogen can be moderately compatible $\left(K_{N}=2\right)$ in diamond under reduced conditions and strongly compatible $\left(K_{N}=4\right)$, when diamond formed from an oxidized fluid. Mentioned conceptions of nitrogen partitioning at diamond crystallization based on model thermodynamic calculations and on empirical modeling of general distribution of nitrogen concentrations in mantle diamonds vs. their carbon isotopic composition. There is no doubt that this approach can be valid for modeling the distribution of nitrogen between bulk fluid and bulk diamond. Our data cannot provide any evidence of fractionation between bulk fluid and bulk diamond since there is no data about nitrogen concentrations in the fluid is available in our experiments. However, it is clear from our experiments that the nitrogen is strongly incompatible to diamond when atomic-flat faces of cube are growing. Most cuboid sectors reported in natural samples from kimberlites, lamproites and associated placers are, in fact, atomic-rough. Therefore, it is rather difficult to expect an exact fit of compositional difference resulted from the surface-induced fractionation in natural and synthetic crystals.

The first reported natural diamonds with flat cube faces found in Tibetan ophiolites [32] reveal the same nitrogen distribution pattern between $\{111\}$ and $\{100\}$ growth sectors as has been seen in synthetic crystals. Three natural crystals gave $\mathrm{N}_{(111)} / \mathrm{N}_{(100)}$ ratios from 5.3 to 8.8 [32]. The paragenesis of the studied ophiolite, including native elements, alloys, carbides and nitrides, pointed strongly towards highly reducing conditions.

A number of specific conditions must be met in order for such a fractionation mechanism to be active for both carbon isotopes and nitrogen concentration during diamond growth. First, crystallization should take place from a carbon rich solution. Secondly, growth must occur predominantly on atomic-flat surfaces of different crystallographic faces. Diamond crystallization is generally associated with low degree of melting of a silicate-dominated matrix within the Earth's mantle. However, this melting must be advanced enough to provide crystallization of euhedral macrocrystals, and it would be reasonable to expect a significant concentration of carbon clusters in coordinated groups in these melts. As mentioned, high association of carbon in a solution leads to the suppression of growth on all crystal faces other than octahedra. Such a situation would explain the overwhelming dominance of octahedra during the crystallization of natural diamonds.

Another important parameter that affects fractionation is growth rate: diamond growth rate has a significant influence on the carbon isotope fractionation between diamond and the carbon solution in metal melt [16]. Presumably, the ability of surface-induced fractionation to be recorded within a crystal depends on the ratio of isotope diffusion rate over crystal growth rate. Because the growth rate is considered as one of the major parameters determining diamond crystal habit [33], this parameter could be of interest for further investigations.

Some natural environments should be favorable for diamond crystallization associated with a relatively low degree of association of carbon atoms in coordinated groups. One such example would be a "magma ocean" setting, such as that which dominated during Earth's early history [34], where the temperature regime and compositional gradients were able to provide conditions for atom-by-atom crystallization. A second environment favoring a low degree of association would be a metal rich environment of lower mantle, where diamond could precipitate from carbon dissolved in metal melts. As can be seen from experiments, metal-carbon systems are most conducive for a stable growth of cube faces and surfaces other than octahedra. A third such environment would be melts from subducted carbonates containing minor quantities of silicates and relatively high amount of biogenic carbon, such as those generating carbonaceous diapirs [35] or during interaction of carbonates with reduced mantle material [36]. Such setting would have the potential to provide conditions that would form diamond crystals with the surface-induced compositional inhomogeneity, such as we observed in our experiments including the carbonate system. 


\section{Samples and Methods}

Two samples of synthetic diamond were prepared in the $\mathrm{Na}_{2} \mathrm{CO}_{3}-\mathrm{CO}_{2}-\mathrm{C}$ system. The composition of the system was chosen to provide diamond crystallization near the Carbon-Carbon oxide (CCO) buffer from a single carbon source rather than modelling some specific geological situation. However, sodium carbonates were found in fresh kimberlites $[37,38]$ and even as inclusions in diamonds $[38,39]$ and in olivine recovered from kimberlites [40].

Natural diamond crystals with cubic and octahedral to dodecahedral habits and near $0.5 \mathrm{~mm}$ in size were used as seed crystals in our experiments. Both morphological types of seeds were placed together at the bottom of a platinum ampoule and the ampoule was filled with $99.99 \%$ pure sodium oxalate $\left(\mathrm{Na}_{2} \mathrm{C}_{2} \mathrm{O}_{4}\right)$. Finally, the ampoule was hermetically welded using a carbon-free technique. High-pressure experiments used a "split-sphere" type (BARS) multianvil apparatus at $1400{ }^{\circ} \mathrm{C}$ and $6 \mathrm{GPa}$ in the V.S. Sobolev Institute of Geology and Mineralogy SB RAS [41]. Sodium oxalate decomposes at experimental conditions producing sodium carbonate fluid $\left(\mathrm{CO}_{2}\right.$-containing $\mathrm{Na}_{2} \mathrm{CO}_{3}$ melt $)$ with about $4.5 \mathrm{wt} \%$ excess of carbon. This excess of carbon in the carbonate fluid prevents diamond seeds from dissolution, a phenomenon often seen in metal-carbon systems and leads to the seeds being overgrown by synthetic diamond material with maximum thickness of $120 \mu \mathrm{m}$ Diamond crystals recovered from the ampoules were inspected for growth morphology as described in [42], then cut in a parallel [110] direction, polished and examined using a Philips XL30CP scanning electron microscope (Philips, Germany) with attached CL detector at the Edinburgh University, thereby revealing internal structure within the samples.

Secondary Ion Mass-Spectrometry data of carbon and nitrogen isotopes and nitrogen abundance were collected using the CAMECA 1270 ion microprobe (AMETEK Inc., France) at the NERC/Edinburgh University Ion Microprobe Facility (EIMF), in 2005-2006 and the CAMECA 1280 HR at the GFZ Potsdam SIMS laboratory in 2015-2016.

The analytical conditions for the EIMF measurements where reported earlier [5]. In all cases, the unknowns and reference material were placed adjacent to one another in the same indium mount. The surface of the 1-inch sample mounts were then cleaned using high-purity ethanol prior to being argon sputter coated with high-purity gold. Magnet calibration and centring of the field aperture and slits was done prior to each point analysis.

At the GFZ Potsdam SIMS facility, carbon and nitrogen data were collected in June 2015 and March 2016, respectively. As for earlier EIMF work, for the GFZ measurements we employed ${ }^{133} \mathrm{Cs}+$ primary beam with a total impact energy of $20 \mathrm{keV}$. Our analyses used a $250 \mathrm{pA}$ probe current for nitrogen and $2.5 \mathrm{nA}$ current for carbon. The beam was focused to a $\sim 4-8 \mu \mathrm{m}$ diameter with a Gaussian distribution at the sample surface. Secondary ions were extracted using a $-10 \mathrm{kV}$ potential applied to the sample holder. Charge compensation involved circa $250 \mathrm{pA}$ low energy electron cloud provide by a normal incidence electron flood gun. The instrument was operated with a circa $80 \mu \mathrm{m}$ field-of-view, with a $50 \mathrm{eV}$ wide energy window. In the case of the carbon isotope measurements, we used a static multi-collection mode operating at a mass resolution of $\mathrm{M} / \mathrm{dM} \approx 3200$, which fully resolves the ${ }^{13} \mathrm{C}$ mass station from the nearby ${ }^{12} \mathrm{C}^{1} \mathrm{H}$ molecular isobar. For determining nitrogen contents and nitrogen isotope ratios, our mass spectrometer was operated in mono-collection mode at a mass resolution of $\mathrm{M} / \mathrm{dM} \approx 6900$ using the peak-stepping sequence ${ }^{12} \mathrm{C}_{2},{ }^{12} \mathrm{C}^{14} \mathrm{~N}$ and ${ }^{12} \mathrm{C}^{15} \mathrm{~N}$ signals.

Each carbon isotope analysis was preceded by a $60 \mathrm{~s}$ presputter using a $25 \mu \mathrm{m}$ raster, so as to remove the $35 \mathrm{~nm}$ tick gold coat and also to implant $\mathrm{Cs}+$ in order to establish equilibrium sputtering conditions. An analysis used a $15 \mu \mathrm{m}$ raster, together with the tool's dynamic transfer capability, thereby generating a square, flat-bottom sputter crater. Prior to initiating data collection, we conducted automatic beam centering routines in both $x$ and $y$ for the field aperture. A single carbon analysis involved 20 cycles of $4 \mathrm{~s}$ integration each and the data were filtered at the $3 \mathrm{sd}$ level. Thus, a single analysis required around $3 \mathrm{~min}$ of analysis time, including the presputtering. All data were collected in fully automated data acquisition mode. 
Prior to initiating nitrogen data collection on a selected target, the region was sputter cleaned for $80 \mathrm{~s}$ using a $3 \mathrm{nA}$ Cs + primary beam rastered over a $20 \times 20 \mu \mathrm{m}$ area. Prior to initiating data collection, the primary beam current was reduced to the $250 \mathrm{pA}$ probe current and the rastered area was reduced to $10 \times 10 \mu \mathrm{m}$, which was compensated for using the dynamic transfer function of tool. Automatic centering routines were then conducted for $x$ and $y$ for the field aperture. Our data acquisition involved the peak-stepping sequence: ${ }^{12} \mathrm{C}_{2}$ (2 s integration time per cycle), ${ }^{12} \mathrm{C}^{14} \mathrm{~N}(4 \mathrm{~s})$ and ${ }^{12} \mathrm{C}^{15} \mathrm{~N}(15 \mathrm{~s})$. A single nitrogen analysis consisted of 50 cycles of this peak-stepping sequence, leading to a total analysis time of $\sim 20$ min per acquisition.

For the EIMF measurements, the "synAT" standard (a synthetic " $\mathrm{A}$ " diamond crystal, partial slice " $\mathrm{T}^{\prime}$ ) was used [43]. The characteristics of this reference material are: $230.4 \mathrm{ppm} \mathrm{N}(\mathrm{wt})$ and $\delta^{13} \mathrm{C}_{\mathrm{PDB}}$ of $-23.92 \%$ as determined by combustion analysis using a gas source mass spectrometer (analysed by S.R. Boyd, at the Laboratoire de Geochimie des Isotopes Stables, Université de Paris VII). The GFZ machine calibration used two diamond reference materials contained in the same indium-based sample mount. The samples were cut out from "steady state" parts of up-octahedral sectors in synthetic crystals $140 / 4$ and 150/3 [5]. The synthetic crystals had been characterized for their $\delta^{13} \mathrm{C}_{\mathrm{VPDB}}$ values and nitrogen contents refer to "SynAT" reference material during the EIMF sessions in 2005 and 2006. Minor pieces of the specific chips used in this study were additionally checked for their $\delta^{13} \mathrm{C}, \delta^{15} \mathrm{~N}$ and nitrogen content using static vacuum gas source mass-spectrometry by Dr. A. Verchovsky at Open University (Milton Keynes, UK). The established characteristics are as follows: Crystal 140/4 with $\delta^{13} \mathrm{C}_{\mathrm{VPDB}}=-26.5 \%, 460 \mu \mathrm{g} / \mathrm{g}$ nitrogen and $\delta^{15} \mathrm{~N}_{\mathrm{AIR}}=0 \%$; Crystal 150/3 with $\delta^{13} \mathrm{C}_{\mathrm{VPDB}}=-24.5 \%, 215 \mu \mathrm{g} / \mathrm{g}$ nitrogen and $\delta^{15} \mathrm{~N}_{\mathrm{AIR}}=-5 \%$.

Our carbon isotope raw data were tested for the presence of a time dependent linear drift, which was corrected for when needed. Such drifts, which we attribute to changes in sensitivity of the amplifiers in our detector system, were $0.01 \%$ per hour or less. After correcting for such drift, the repeatability of our ${ }^{13} \mathrm{C} /{ }^{12} \mathrm{C}$ determinations on the two reference materials was less than $0.24 \%$ ( $\left.1 \mathrm{sd}\right)$, which is our best estimate for the random component that might be present in our carbon isotope data. Hence, we can conclude that the overall reliability of our $\delta^{13} \mathrm{C}$ values is better than $\pm 0.24 \%$ ( $1 \mathrm{sd}$ ) for GFZ measurements. The uncertainty of individual $\mathrm{N}$ abundance data points reported for the studied samples are better than $\pm 10 \%$. These uncertainties represent one standard error of the mean based upon multiple analyses of restricted areas within the reference crystals.

$\mathrm{Ab}$ initio calculations of $\mathrm{C}$ isotope fractionation factors were performed following the procedure of Kowalski et al. [44,45] for calculation of isotope fractionation factors at high temperatures. This method utilizes the Bigeleisen and Mayer [46] approximation, in which only the force constants acting on the fractionating atom of interest are computed and used in derivation of relevant fractionation factors. This approach has been successfully applied in calculation of Li and B isotope fractionation between complex minerals and fluids [44,45]. For the quantum mechanical calculations of the force constants, we used plane-wave DFT code CPMD [47] with BLYP generalized gradient approximation [48,49] and energy cutoff of 140 Ryd. The norm conserving Goedecker pseudopotentials were applied to describe the core electrons [50]. Beta factors, describing isotope fractionation between species and an ideal monoatomic gas, were computed for three diamond surfaces (100), (110) and (111) with the bulk lattice parameter of face-centered cubic Bravais lattice of $3.56669 \AA$ [51]. The surfaces were modelled with thick $2 \times 2$ multi-layer slabs separated by a thick layer of vacuum in the $z$-direction (at least $12.9 \AA$ thick) and the atoms of the bottom layer were fixed to the bulk positions. The modelled slabs contained 17, 13 and 10 layers for (100), (110) and (111) surfaces, respectively.

\section{Conclusions}

Our results univocally evidence that compositional heterogeneity can occur in diamonds because of crystallochemically controlled fractionation. Difference in atom's arrangements on atomic-flat faces of octahedra, cube and other faces provide measurable contrast in fractionation of carbon isotopes and nitrogen impurity between crystal and growth media on the certain crystal faces. This effect is equally 
occurs at both reduced and oxidized conditions and the cubic grown diamond have up to $4 \%$ lighter carbon isotope composition in comparison with the octahedral grown diamond. At the same time, the cubic grown diamond contain 2 to 20 times less nitrogen content pointing generally incompatible behavior of the nitrogen in diamond. Due to limited diffusion in diamond lattice, the difference in composition of sectors of cube and octahedra will survive through the geological timescale even at mantle temperatures and can be seen in some natural diamond crystals.

Presumably high degree of carbon association in natural mantle fluids makes atomic-flat faces of octahedra dominant at diamond crystallization. As a result, natural diamonds are growing mainly by atomic-flat faces of octahedra or atomic-rough faces of cube. Such conditions reducing the significance of surface-induced carbon and nitrogen fractionation for natural diamonds. However, identification of the compositional pattern examined here within natural diamonds can provide a key for evaluation of degree of carbon association in the mantle fluid.

Supplementary Materials: Supplementary materials can be found at www.mdpi.com/2073-4352/7/7/190/s1. Table S1 contains all the SIMS data of $\delta^{13} \mathrm{C}$ and nitrogen abundances measured within natural seeds and synthetic rims of particular samples. Statistical accounts of all the data are available for particular crystallography. Errors $(1 \sigma)$ are $0.2 \%$ for $\delta^{13} \mathrm{C}$ values and $10 \%$ for nitrogen abundances. Regular numbers were measured in the Edinburgh microprobe facility. Bold numbers were measured in the GFZ Potsdam SIMS laboratory.

Acknowledgments: Members of the EIMF (Edinburgh ion Microprobe Facility) particularly supporting this work were: Ben Harte (provided the opportunity for initial steps of the research), John Craven (tuning and maintenance of the Cameca IMS 1270 instrument), Nicola Cayzer (collection of CL images by SEM). The help of Sasha Verchovsky (Open University) in obtaining and characterizing standards is much appreciated. The authors are grateful for research support from the United Kingdom NERC (grant NER/A/S/2003/00368) in part for allowing use of the EIMF facility in 2005-2006. We thank Frederic Couffignal for his excellent support during SIMS data acquisition at GFZ Potsdam. The latter part of study was supported by a grant from the Russian Scientific Foundation (project No. 14-27-00054).

Author Contributions: Vadim N. Reutsky conceived the idea of the research, managed opportunities, summarized and interpreted the data, and prepared the manuscript, Piotr M. Kowalski performed ab initio calculations, Yury N. Palyanov designed and performed the experiments, and EIMF and Michael Wiedenbeck contributed SIMS instruments and infrastructure for high spatial resolution isotope analysis.

Conflicts of Interest: The authors declare no conflict of interest. The founding sponsors had no role in the design of the study; in the collection, analyses, or interpretation of data; in the writing of the manuscript, and in the decision to publish the results.

\section{References}

1. Strong, H.M.; Chrenko, R.M. Properties of Laboratory-Made Diamond. J. Phys. Chem. 1971, 76, 1838-1843. [CrossRef]

2. Boyd, S.R.; Pillinger, C.T.; Milledge, H.J.; Mendelssohn, M.J.; Seal, M. Fractionation of nitrogen isotopes in a synthetic diamond of mixed crystal habit. Nature 1988, 133, 604-607. [CrossRef]

3. Burns, R.C.; Cvetkovic, V.; Dodge, C.N.; Evans, D.J.F.; Rooney, M.T.; Spear, P.M.; Welbourn, C.M. Growth-sector dependence of optical features in large synthetic diamonds. J. Cryst. Growth 1990, 104, 257-279. [CrossRef]

4. Watt, G.A.; Newton, M.E.; Baker, J.M. EPR and optical imaging of the growth-sector dependence of radiation-damage defect production in synthetic diamond. Diam. Relat. Mater. 2001, 10, 1681-1683. [CrossRef]

5. Reutsky, V.N.; Harte, B.; EIMF; Borzdov, Y.M.; Palyanov, Y.N. Monitoring diamond crystal growth, a combined experimental and SIMS study. Eur. J. Mineral. 2008, 20, 365-374. [CrossRef]

6. Schwarz, S.; Rottmair, C.; Hirmke, J.; Rosiwal, S.; Singer, R.F. CVD-diamond single-crystal growth. J. Cryst. Growth 2004, 271, 425-434. [CrossRef]

7. Bulanova, G.P.; Pearson, D.G.; Hauri, E.H.; Griffin, B.J. Carbon and nitrogen isotope systematics within a sector-growth diamond from the Mir kimberlite, Yakutia. Chem. Geol. 2002, 188, 105-123. [CrossRef]

8. Cartigny, P.; Harris, J.W.; Taylor, A.; Davies, R.; Javoy, M. On the possibility of a kinetic fractionation of nitrogen stable isotopes during natural diamond growth. Geochim. Cosmochim. Acta 2003, 67, 1571-1576. [CrossRef] 
9. Reutsky, V.N.; Zedgenizov, D.A. Some specific features of genesis of microdiamonds of octahedral and cubic habit from kimberlites of the Udachnaya pipe (Yakutia) inferred from carbon isotopes and main impurity defects. Russ. Geol. Geophys. 2007, 48, 299-304. [CrossRef]

10. Zedgenizov, D.A.; Harte, B. Microscale variations of $\delta^{13} \mathrm{C}$ and $\mathrm{N}$ content in diamonds with mixed-habit growth. Chem. Geol. 2004, 205, 169-175. [CrossRef]

11. Howell, D.; Griffin, W.L.; Piazolo, S.; Say, J.M.; Stern, R.A.; Stachel, T.; Nasdala, L.; Rabeau, J.R.; Pearson, N.J.; O'Reilly, S.Y. A spectroscopic and carbon-isotope study of mixed-habit diamonds: Impurity characteristics and growth environment. Am. Miner. 2013, 98, 66-77. [CrossRef]

12. Howell, D.; Stern, R.A.; Griffin, W.L.; Southworth, R.; Mikhail, S.; Stachel, T. Nitrogen isotope systematics and origins of mixed-habit diamonds. Geochim. Cosmochim. Acta 2015. [CrossRef]

13. Pal'yanov, Y.N.; Khokhryakov, A.F.; Borzdov, Y.M.; Sokol, A.G.; Gusev, V.A.; Rylov, G.M.; Sobolev, N.V. Growth conditions and the real structure of synthetic diamond crystals. Geol. Geofiz. 1997, 38, 882-906.

14. Jablon, B.M.; Navon, O. Most diamonds were created equal. Earth Planet. Sci. Lett. 2016, 443, 41-47. [CrossRef]

15. Babich, Y.V.; Feigelson, B.N. Spatial distribution of the nitrogen defects in synthetic diamond monocrystals: Data of IR mapping. Geochem. Int. 2009, 47, 94-98. [CrossRef]

16. Reutsky, V.N.; Borzdov, Y.M.; Palyanov, Y.N. Effect of diamond growth rate on carbon isotope fractionation in Fe-Ni-C system. Diam. Relat. Mater. 2012, 21, 7-10. [CrossRef]

17. Palyanov, Y.N.; Borzdov, Y.M.; Khokhryakov, A.F.; Kupriyanov, I.N.; Sokol, A.G. Effect of nitrogen impurity on diamond crystal growth processes. Cryst. Growth Des. 2010, 10, 3169-3175. [CrossRef]

18. Stroitelev, S.A. Crystal Chemical Aspect of Semiconductor Technology; Nauka: Novosibirsk, Russia, 1976; 192p. (In Russian)

19. Chernov, A.A. Stability of faceted shapes. J. Cryst. Growth 1971, 24-25, 11-31. [CrossRef]

20. Bottinga, Y. Carbon isotope fractionation between graphite, diamond and carbon dioxide. Earth Planet. Sci. Lett. 1969, 5, 301-307. [CrossRef]

21. Richet, P.; Bottinga, Y.; Javoy, M. A review of hydrogen, carbon, nitrogen, oxygen, sulphur, and chlorine stable isotope fractionation among gaseous molecules. Annu. Rev. Earth Planet. Sci. 1977, 5, 65-110. [CrossRef]

22. Deines, P. The carbon isotopic composition of diamonds: Relationship to diamond shape, color, occurrence and vapor composition. Geochim. Cosmochim. Acta 1980, 44, 943-961. [CrossRef]

23. Reutsky, V.N.; Palyanov, Y.N.; Borzdov, Y.M.; Sokol, A.G. Isotope fractionation of carbon during diamond crystallization in model systems. Russ. Geol. Geophys. 2015, 56, 239-244. [CrossRef]

24. Koga, K.T.; Van Orman, J.A.; Walter, M.J. Diffusive relaxation of carbon and nitrogen isotope heterogeneity in diamond: New thermochronometer. Phys. Earth Planet. Inter. 2003, 139, 35-43. [CrossRef]

25. Galimov, E.M. Isotope fractionation related to kimberlite magmatism and diamond formation. Geochim. Cosmochim. Acta 1991, 55, 1697-1708. [CrossRef]

26. Cartigny, P.; Harris, J.W.; Javoy, M. Diamond genesis, mantle fractionations and mantle nitrogen content: A study of $\delta^{13} \mathrm{C}-\mathrm{N}$ concentrations in diamonds. Earth Planet. Sci. Lett. 2001, 185, 85-98. [CrossRef]

27. Stachel, T.; Harris, J.W.; Muehlenbachs, K. Sources of carbon in inclusion bearing diamonds. Lithos 2009, 112, 625-637. [CrossRef]

28. Smart, K.A.; Chacko, T.; Stachel, T.; Muehlenbachs, K.; Stern, R.A.; Heaman, L.M. Diamond growth from oxidized carbon sources beneath the Northern Slave Craton, Canada: A $\delta^{13} \mathrm{C}-\mathrm{N}$ study of eclogite-hosted diamonds from the Jericho kimberlite. Geochim. Cosmochim. Acta 2011, 75, 6027-6047. [CrossRef]

29. Palot, M.; Pearson, D.G.; Stern, R.A.; Stachel, T.; Harris, J.W. Isotopic constraints on the nature and circulation of deep mantle $\mathrm{C}-\mathrm{H}-\mathrm{O}-\mathrm{N}$ fluids: Carbon and nitrogen systematics within ultra-deep diamonds from Kankan (Guinea). Geochim. Cosmochim. Acta 2014, 139, 26-46. [CrossRef]

30. Petts, D.C.; Chacko, T.; Stachel, T.; Stern, R.A.; Heaman, L.M. A nitrogen isotope fractionation factor between diamond and its parental fluid derived from detailed SIMS analysis of a gem diamond and theoretical calculations. Chem. Geol. 2015, 410, 188-200. [CrossRef]

31. Boyd, S.R.; Pineau, F.; Javoy, M. Modelling the growth of natural diamonds. Chem. Geol. 1994, 116, $29-42$. [CrossRef]

32. Howell, D.; Griffin, W.L.; Yang, J.; Gain, S.; Stern, R.A.; Huang, J.-X.; Jacob, D.E.; Xu, X.; Stokes, A.J.; O'Reilly, S.Y.; et al. Diamonds in ophiolites: Contamination or a new diamond growth environment? Earth Planet. Sci. Lett. 2015, 430, 284-295. [CrossRef] 
33. Sunagawa, I. Growth and morphology of diamond crystals under stable and metastable conditions. J. Cryst. Growth 1990, 99, 1156-1161. [CrossRef]

34. Dasgupta, R.; Chi, H.; Shimizu, N.; Buono, A.S.; Walker, D. Carbon solution and partitioning between metallic and silicate melts in a shallow magma ocean: Implications for the origin and distribution of terrestrial carbon. Geochim. Cosmochim. Acta 2013, 102, 191-212. [CrossRef]

35. Litasov, K.; Ohtani, E. The solidus of carbonated eclogite in the system $\mathrm{CaO}-\mathrm{Al}_{2} \mathrm{O}_{3}-\mathrm{MgO}-\mathrm{SiO}_{2}-\mathrm{Na}_{2} \mathrm{O}-\mathrm{CO}_{2}$ to $32 \mathrm{GPa}$ and carbonatite liquid in the deep mantle. Earth Planet. Sci. Lett. 2010, 295, 115-126. [CrossRef]

36. Palyanov, Y.N.; Bataleva, Y.V.; Sokol, A.G.; Borzdov, Y.M.; Kupriyanov, I.N.; Reutsky, V.N.; Sobolev, N.V. Mantle-slab interaction and redox mechanism of diamond formation. Proc. Natl. Acad. Sci. USA 2013, 110, 20408-20413. [CrossRef] [PubMed]

37. Kamenetsky, V.S.; Maas, R.; Kamenetsky, M.B.; Paton, C.; Phillips, D.; Golovin, A.V.; Gornova, M.A. Chlorine from the mantle: Magmatic halides in the Udachnaya-East kimberlite, Siberia. Earth Planet. Sci. Lett. 2009, 285, 96-104. [CrossRef]

38. Kaminsky, F. Mineralogy of the lower mantle: A review of 'super-deep' mineral inclusions in diamond. Earth Sci. Rev. 2012, 110, 127-147. [CrossRef]

39. Zedgenizov, D.A.; Ragozin, A.L.; Shatsky, V.S.; Araujo, D.; Griffin, W.L. Fibrous diamonds from the placers of the northeastern Siberian Platform: Carbonate and silicate crystallization media. Russ. Geol. Geophys. 2011, 52, 1298-1309. [CrossRef]

40. Sharygin, I.S.; Golovin, A.V.; Korsakov, A.V.; Pokhilenko, N.P. Eitelite in sheared peridotite xenoliths from Udachnaya-East kimberlite pipe (Russia)—A new locality and host rock type. Eur. J. Mineral. 2013, 25, 825-834. [CrossRef]

41. Sokol, A.G.; Borzdov, Y.M.; Palyanov, Y.N.; Khokhryakov, A.F.; Sobolev, N.V. An experimental demonstration of diamond formation in the dolomite-carbon and dolomite-fluid-carbon systems. Eur. J. Mineral. 2001, 13, 893-900. [CrossRef]

42. Khokhryakov, A.F.; Palyanov, Y.N.; Kupriyanov, I.N.; Nechaev, D.V. Diamond crystallization in a $\mathrm{CO}_{2}-\mathrm{rich}$ alkaline carbonate melt with a nitrogen additive. J. Cryst. Growth 2016, 449, 119-128. [CrossRef]

43. Harte, B.; Fitzsimons, I.C.W.; Harris, J.W.; Otter, M.L. Carbon isotope ratios and nitrogen abundances in relation to cathodoluminescence characteristics for some diamonds from the Kaapvaal Province, S. Africa. Mineral. Mag. 1999, 63, 829-856. [CrossRef]

44. Kowalski, P.M.; Jahn, S. Prediction of equilibrium Li isotope fractionation between minerals and aqueous solutions at high P and T: An efficient ab initio approach. Geochim. Cosmochim. Acta 2011, 75, 6112-6123. [CrossRef]

45. Kowalski, P.M.; Wunder, B.; Jahn, S. Ab initio prediction of equilibrium boron isotope fractionation between minerals and aqueous fluids at high P and T. Geochim. Cosmochim. Acta 2013, 101, 285-301. [CrossRef]

46. Bigeleisen, J.; Mayer, M.G. Calculation of equilibrium constants for isotopic exchange reactions. J. Chem. Phys. 1947, 15, 261-267. [CrossRef]

47. Marx, D.; Hutter, J. Ab initio molecular dynamics: Theory and implementation. In Modern Methods and Algorithms of Quantum Chemistry; Grotendorst, J., Ed.; NIC: FZ Juelich, Germany, 2000; pp. 301-449.

48. Becke, A.D. Density-functional exchange-energy approximation with correct asymptotic behavior. Phys. Rev. 1988, 38, 3098-3100. [CrossRef]

49. Liu, Y.; Tossell, A. Ab initio molecular orbital calculations for boron isotope fractionations on boric acids and borates. Geochim. Cosmochim. Acta 2005, 69, 3995-4006. [CrossRef]

50. Goedecker, S.; Teter, M.; Hutter, J. Separable dual-space Gaussian pseudopotentials. Phys. Rev. B 1996, 54, 1703-1710. [CrossRef]

51. Straumanis, M.E.; Aka, E.Z. Precision determination of lattice parameter, coefficient of thermal expansion and atomic weight of carbon in diamond. J. Am. Chem. Soc. 1951, 73, 5643-5646. [CrossRef]

(C) 2017 by the authors. Licensee MDPI, Basel, Switzerland. This article is an open access article distributed under the terms and conditions of the Creative Commons Attribution (CC BY) license (http://creativecommons.org/licenses/by/4.0/). 